\title{
Standing Height and its Estimation Utilizing Foot Length Measurements in Adolescents from Western Region in Kosovo
}

\author{
Stevo Popovic, Jovan Gardasevic and Bojan Masanovic \\ University of Montenegro, Faculty for Sport and Physical Education, Niksic, Montenegro \\ Fitim Arifi \\ University of Montenegro, Faculty for Sport and Physical Education, Niksic, Montenegro \\ AAB College, Faculty of Physical Education and Sport, Pristina, Kosovo \\ Dusko Bjelica \\ University of Montenegro, Faculty for Sport and Physical Education, Niksic, Montenegro
}

\begin{abstract}
A B S T R A C T
The purpose of this research is to examine standing height in both Kosovan genders in the Western Region as well as its association with foot length, as an alternative to estimating standing height. A total of 664 individuals (338 male and 326 female) participated in this research. The anthropometric measurements were taken according to the protocol of ISAK. The relationships between body height and foot length were determined using simple correlation coefficients at a ninety-five percent confidence interval. A comparison of means of standing height and foot length between genders was performed using a t-test. After that a linear regression analysis were carried out to examine extent to which foot length can reliably predict standing height. Results displayed that Western Kosovan male are $179.71 \pm 6.00 \mathrm{~cm}$ tall and have a foot length of $26.73 \pm 1.20 \mathrm{~cm}$, while Western Kosovan female are $166.26 \pm 5.23 \mathrm{~cm}$ tall and have a foot length of $23.66 \pm 1.06 \mathrm{~cm}$. The results have shown that both genders made WesternKosovans a tall group, a little bit taller that general Kosovan population. Moreover, the foot length reliably predicts standing height in both genders; but, not reliably enough as arm span. This study also confirms the necessity for developing separate height models for each region in Kosovo as the results from Western-Kosovans don't correspond to the general values.
\end{abstract}

Key words: prediction, measurement, stature, foot length, Kosovan

\section{Introduction}

According to Komunat e Kosovës (2013), Kosovo is a democratic, multi-ethnic and secular republic which administratively is subdivided into seven districts (Ferizaj, Gjakova, Gjilan, Mitrovica, Peja, Pristina and Prizren) and five regions (Eastern, Western, Northern, Southern and Central). This study analyzes the standing height and its estimation utilizing foot length measurements in adolescents in western region which contains two districts (Peja and Djakova) and seven municipalities (Deçan, Gjakova, Junik, Rahovec, Pejë, Istok and Klina). This region (Figure 1) covers the area of 2,494 square kilometers and has population of 368,907 inhabitants, while average density per square kilometer is 150 inhabitants (Komunat e Kosovës, 2013). Although Kosovo doesn't have too big territory, it has a very varied relief that mostly belongs to Dinarides range and the author assumed this fact might influence the main objective of this study, because of the type of the soil as well as other socio-economical and geographical characteristics as a potential influencing factors (Arifi, 2017; Arifi, Sermaxhaj, Zejnullahu-Raçi, Alaj, \& Metaj, 2017b).

There are lots of scientific findings which confirms that the measurement of standing height is a vitally important variable when assessing nutritional status (cited in Arifi et al., 2017a; Datta Banik, 2011; Popovic \& Bjelica, 2016), as well as when assessing the growth of children, evaluating the basic energy

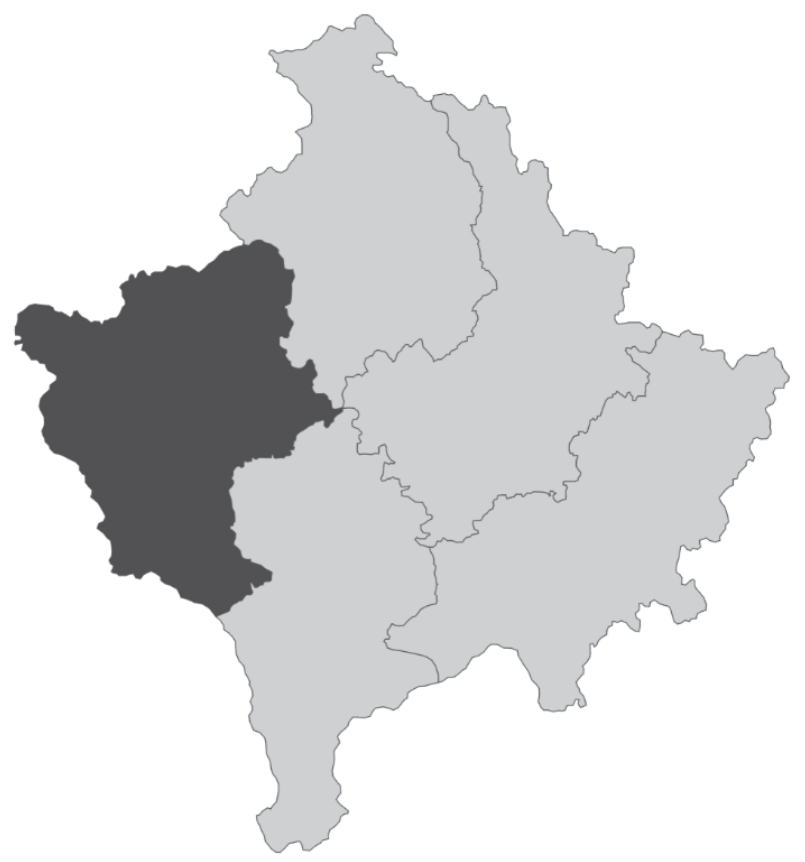

Figure 1. Geographical Location of Western Region in Kosovo 
requirements, adjusting the measures of physical capacity and predicting the drug dosage and setting standards of physiological variables such as muscle strength, metabolic rate, lung volumes and glomerular filtration (Golshan, Amra, \& Hoghogi, 2003; M. Golshan, Crapo, Amra, Jensen, \& R. Golshan, 2007; Mohanty, Babu, \& Nair, 2001; Ter Goon, Toriola, Musa, \& Akusu, 2011). However, according to Quanjer and his collaborators (2014), the exact standing height cannot always be identified and resolved in the usual way (e.g. paralysis, fractures, amputation, scoliosis and pain). Because of these factors, an estimate of standing height has to be acquired from other reliable anthropometric indicators such as hand and foot lengths, knee height, length of the forearm, length of the sternum, vertebral column length, sitting height, length of scapula, arm span as well as cranial sutures, skull, facial measurements et cetera (cited in Gardasevic, Rasidagic, Krivokapic, Corluka, \& Bjelica, 2017; Popovic, 2017). Therefore, all these anthropometric indicators, which are used as an alternative to estimate standing height, are very important in predicting loss in standing height connected with aging. Also, to diagnose individuals with disproportionate growth abnormalities and skeletal dysplasia or standing height loss during surgical procedures on the spine (Mohanty et al., 2001), as well as to anticipate standing height in many older people as it is very difficult to measure it precisely, and sometimes impossible because of mobility problems and kyphosis (Hickson \& Frost, 2003). Lastly, it is important to state that this knowledge finds its importance in sport since the standing height represents a significant factor which influences the success in various sport disciplines (Popovic, 2017).

Several researches have reported the benefit of using various body parameters in predicting standing height, and arm span happened to be one of the most reliable ones in adults (Hickson \& Frost, 2003; Jalzem \& Gledhill, 1993; Mohanty et al., 2001; Ter Goon et al., 2011), while foot length measurement is the most reliable predictor during adolescent age, due to the fact that ossification and maturation occurs earlier in the foot than the long bones and standing height could be more accurately predicted from foot measurement as compared to long bones during adolescent age (cited in Singh, Kumar, Chavali, \& Harish, 2012). In addition, the relationship of long bones and standing height was found to vary in different ethnic and racial groups (Bjelica, Popovic, Kezunovic, Petkovic, Jurak, \& Grasgruber, 2012; Brown, Feng, \& Knapp, 2002; Popovic, Bjelica, Georgiev, Krivokapic, \& Milasinovic, 2016; Popovic, Bjelica, Molnar, Jaksic, \& Akpinar, 2013; Popovic, Bjelica, Tanase, \& Milasinovic, 2015; Reeves, Varakamin, \& Henry, 1996; Steele $\&$ Chenier, 1990) as well as various regions (Arifi, 2017; Arifi et al., 2017b; Milasinovic, Popovic, Matic, Gardasevic, \& Bjelica, 2016; Milasinovic, Popovic, Jaksic, Vasiljevic, \& Bjelica, 2016). Hence, researchers have derived a specific formula for calculating standing height from long bones for each ethnic/race group. The mentioned variations might be the case with foot length predictions too, mostly due to the fact that the Dinaric Alps population has specific body composition than national as well as regional point of view (Popovic, 2017). Even though many studies with this essence are available on neighboring countries as well as worldwide population, only narrow data is available on Kosovan subjects, just one conducted by Popovic and his collaborators (Popovic, Arifi, \& Bjelica, 2017; Popovic \& Bjelica, 2017) that has covered whole Kosovan population, while there were no regional analyses so far. Considering rather sparse recent scientific literature, the purpose of this research was to examine the standing height in both WesternKosovan genders and its association with foot length.

\section{Methods}

The nature of this research gave extension to the 664 highschool students last year (338 male and 326 female) from Western Region of Kosovo to be subjects. Two reasons which qualified the selected individuals are: the first is related to the fact that the growth of an individual ceases by this age, while the second is related to the fact that there is no age-related loss in standing height at this age. The average age of the male subject was $18.24 \pm 0.43$ years old (range $18-20$ years), while the average age of the female subject was $18.25 \pm 0.45$ years old (range 18-20 years). It is important to underline that the researchers have excluded from the data analysis of the individuals with physical deformities as well as those without informed consent. The exclusion criterion was also being non-Western Kosovan.

The anthropometric measurements, including standing height and foot length, were taken according to the protocol of the International Society for the Advancement of Kinanthropometry (Marfell-Jones, Olds, Stew, \& Carter, 2006). The trained measurers have measured selected anthropometric indicators (same measurer for each indicator), while the quality of their performance was evaluated against the prescribed "ISAK Manual". Lastly, the age of the each subject was reached directly from the birthdays.

The analysis were performed by using the Statistical Package for Social Sciences (SPSS) version 20.0. Means and standard deviations (SD) were obtained for both anthropometric variables. A comparison of means of standing height and foot length between genders was performed using a t-test. The relationships between standing height and foot length were determined using simple correlation coefficients at ninety-five percent confidence interval. Then a linear regression analysis were carried out to examine the extent to which the foot length can reliably predict standing height. Statistical significance was set at $\mathrm{p}<0.05$.

\section{Results}

A summary of the anthropometric measurements in both genders is shown in Table 1. The mean of the standing height for male was $179.71 \pm 6.00$ centimeters and foot length was $26.73 \pm 1.20$ centimeters, while for female the standing height was $166.26 \pm 5.23$ centimeters and foot length was $23.66 \pm 1.06$ centimeters. The sex difference between standing height and foot length measurements was statistically significant (standing height: $\mathrm{t}=30.759 ; \mathrm{p}<0.000$, and foot length: $\mathrm{t}=29.802 ; \mathrm{p}<0.000$ ).

Table 1. Anthropometric Measurements of the Study Subjects

\begin{tabular}{ccc}
\hline Subjects & $\begin{array}{c}\text { Body Height Range } \\
(\text { Mean } \pm \text { SD) }\end{array}$ & $\begin{array}{c}\text { Foot Length Range } \\
(\text { Mean } \pm \text { SD) }\end{array}$ \\
\hline \multirow{2}{*}{ Male } & $163.5-196.4$ & $22.10-29.80$ \\
& $(179.71 \pm 6.00)$ & $(26.73 \pm 1.20)$ \\
\multirow{2}{*}{ Female } & $153.3-181.8$ & $21.10-28.30$ \\
& $(166.26 \pm 5.23)$ & $(23.66 \pm 1.06)$ \\
\hline
\end{tabular}


In Table 2. the simple correlation coefficients and their ninety-five percent confidence interval analysis between the anthropometric measurements are displayed. The associations between standing height and foot length were significant $(\mathrm{p}<0.000)$ and high in this sample, regardless of gender (male: 0.634 ; female: 0.628 ).

Table 2. Correlation between Body Height and Foot Length of the Study Subjects

\begin{tabular}{cccc}
\hline Subjects & $\begin{array}{c}\text { Correlation } \\
\text { Coefficient }\end{array}$ & $\begin{array}{c}95 \% \text { confidence } \\
\text { interval }\end{array}$ & $\begin{array}{c}\text { Significance } \\
\text { p-value }\end{array}$ \\
\hline Male & 0.634 & $0.544-0.708$ & $<0.000$ \\
Female & 0.628 & $0.529-0.695$ & $<0.000$ \\
\hline
\end{tabular}

The results of the linear regression analysis are shown in Table 3. The first of all models were extracted by including age as a covariate. However, it was found that the contribution of age was insignificant and therefore the age was dropped and estimations were derived as a univariate analysis. The high val- ues of the regression coefficient (male: 0.634; female: 0.628 ) signify that foot length notably predicts standing height in both Western-Kosovan genders (male: $\mathrm{t}=15.03, \mathrm{p}<0.000$; female: $\mathrm{t}=14.52, \mathrm{p}<0.000)$, which confirms the R-square $(\%)$ for the male (40.2) as well as for the female (39.4).

Table 3. Results of Linear Regression Analysis Where the Foot Length Predicts the Body Height

\begin{tabular}{cccccc}
\hline Subjects & $\begin{array}{c}\text { Regression } \\
\text { Coefficient }\end{array}$ & $\begin{array}{c}\text { Standard } \\
\text { Error (SE) }\end{array}$ & R-square (\%) & t-value & p-value \\
\hline Male & 0.634 & 4.647 & 40.2 & 15.03 & 0.000 \\
Female & 0.628 & 4.078 & 39.4 & 14.52 & 0.000 \\
\hline
\end{tabular}

The associations between foot length measurements and standing height among the above models is sketched as a scatter

diagrams (Figure 2).

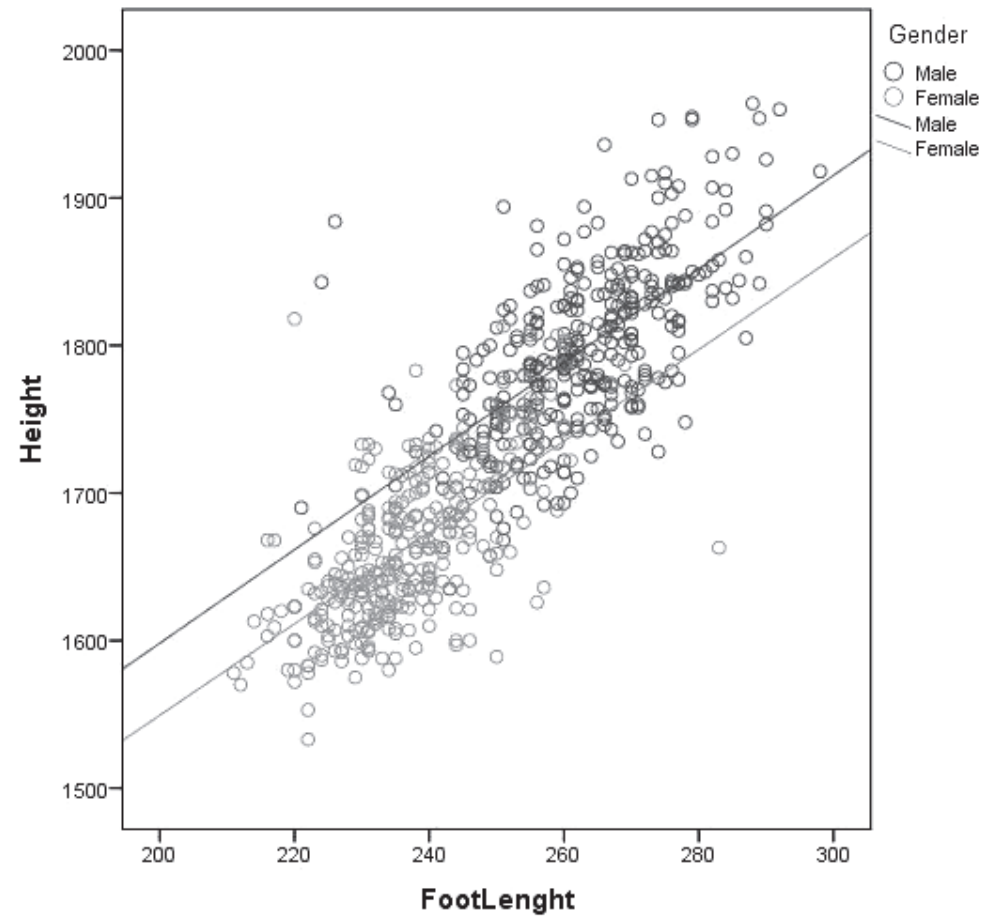

Figure 2. Scatter Diagram and Relationship between Foot Length Measurements and Body Height among Both Genders

\section{Discussion}

The assessment of standing height using various anthropometric measures is very typical from the past centuries and it has been attempted to be studied by many researchers. However, it is important to underline that the arm span has been obtained as the most reliable body indicator for predicting the standing height of an individual (Mohanty et al., 2001; Ter Goon et al., 2011), while foot length is was very close (Kanchan et al., 2008; Singh et al., 2012; Uhrova et al., 2015). In parallel, it is important to emphasize that the individual and ethnic variations referring to standing height and its association with foot length might vary from ethnic group to ethnic group as well as race to race, because the racial and ethnic differences are affective on these measures and reduce the possibility of generalizing (cited in Bjelica et al., 2012). This fact confirms the study conducted by Chinese authors (Cheng et al., 1998) who confirmed a very high linear correlation between standing height and foot length in both genders, as well as in another study which confirmed that foot length can explain up to $77 \%$ variations in standing height (cited in Uhrova et al., 2015), while the research study conducted by Uhrova and her collaborators (Uhrova et al., 2015) shows significant correlation between standing height and all measure anthropometric parame- 
ters in both genders of Slovak population. The highest correlation coefficient in this population was found for foot length in males $(\mathrm{r}=0.71)$ as well as in females $(\mathrm{r}=0.63)$.

All above-mentioned have confirmed the necessity for developing separate standing height models for each population on account of ethnic differences and the recent study conducted by Popovic and his collaborators (Popovic et al., 2017; Popovic $\&$ Bjelica, 2017) who have analyzed the entire Kosovan population and have found specific correlation coefficient in Kosovan male $(\mathrm{r}=0.669)$ and female $(\mathrm{r}=0.625)$ population; however, some recent studies have also confirmed the regional differences between the same ethnic groups too (Arifi, 2017; Arifi et al., 2017b; Milasinovic et al., 2016a; 2016b), which caused the need for additional caution. Therefore, the main goal of this research was to test the hypothesis if above-mentioned facts are true for the Western-Kosovans, that is, for the one of five Kosovan regions. Hence, in the present research it was remarked that the foot length/standing height ratio in Western-Kosovan male is quite lesser (male: $40.2 \%$; female: $39.4 \%$ ) comparing to entire Kosovan (male: $44.3 \%$; female: $38.6 \%$ ) and other available population that estimate over $70 \%$ each and more in male population, while female population is much more in parallel to previously measured populations. As the correlation between foot length and standing height was significant in both Western-Kosovan genders, the foot length measure therefore seems to be a reliable indirect anthropometric indicator for estimating standing height in both genders of Western-Kosovan population. Even though these relations are similar, the estimation equations, which are obtained in the Western-Kosovans, considerably differ from entire Kosovan and other available populations.

The results of the study conducted by Popovic and his collaborators (Popovic et al., 2017; Popovic \& Bjelica, 2017) confirm the necessity for developing separate standing height mod-

\section{R E F E R E N C E S}

Arifi, F. (2017). Stature and its estimation utilizing arm span measurements of both gender adolescents from southern region in Kosovo. Sport Science, 10(1), 92-95.

Arifi, F., Bjelica, D., Sermaxhaj, S., Gardasevic, J., Kezunovic, M., \& Popovic, S. (2017a). Stature and its Estimation Utilizing Arm Span Measurements in Kosovan Adults: National Survey. International Journal of Morphology, 35(3), 1161-1167.

Arifi, F., Sermaxhaj, S., Zejnullahu-Raçi, P., Alaj, I., \& Metaj, Z. (2017b). Stature and its estimation utilizing arm span measurements of both gender adolescents from northern region in Kosovo. Acta Kinesiologica, 11(1), 49-52.

Bjelica, D., Popovic, S., Kezunovic, M., Petkovic, J., Jurak, G. \& Grasgruber, P. (2012). Body Height and Its Estimation Utilizing Arm Span Measurements in Montenegrin Adults. Anthropological Notebooks, 18(2), 69-83.

Brown, J.K., Feng, J.Y. \& Knapp, T.R. (2002). Is self-reported height or arm span a more accurate alternative measure of height? Clinical Nursing Research, 11(4), 417-432.

Cheng, J.C., Leung, S.S., Chiu, B.S., Tse, P.W., Lee, C.W., Chan, A.K., Xia, G., Leung, A.K., \& Xu, Y.Y. (1998). Can we predict body height from segmental bone length measurements? A study of 3,647 children. Journal of Pediatric Orthopaedics, 18, 387-393.

Datta Banik, S. (2011). Arm span as a proxy measure for height and estimation of nutritional status: A study among Dhimals of Darjeeling in West Bengal India. Annals of Human els for both genders in Kosovo but the authors of the same study have recommended that further studies should consider dividing the population of this country to regional subsamples and analyze it separately, just to be sure there are no geographical differences (such as type of the soil) influencing the average standing height in both Kosovan genders as well as its association with foot length. This concern was based on the fact that entire Kosovo doesn't fall into Dinaric Alps racial classification. In parallel, this study confirms the assumption mentioned above and also confirms that it is necessary to develop separate standing height models for each population on account of regional variations in Kosovo.

Next to highlighted issue, the obvious constraint of this research might also be the composition of the measured sample that consisted of high school students. This limitation is based on the fact there are some studies which assumed the growth of an individual doesn't cease by this age (Grasgruber, P., personal communication, 2016; Jurak, G., personal communication, 2017). This assumption might be supported by the fact that university-educated individuals have been founded to be taller than the high school population in Bosnia and Herzegovina (Grasgruber et al., 2017; Gardasevic et al., 2017), Poland (Wronka \& Pawlinska-Chmara, 2009) and Hungary (Szollosi, 1998). On the other hand, this wasn't the truth in Montenegro (Popovic, 2016) and comparing the average standing height measures of this study to the results of some study sampled by university students might give the science much precise conclusions. One more obvious limitation of this study is also the fact that both genders of Kosovo did not reach their full genetic potential yet, since various environmental factors controlled their development. Further continuous monitoring is necessary, mostly due to the reason it is expected the secular changes influencing standing height will ascend in the following two or three decades.
Biology, 38(6), 728-735.

Gardasevic, J., Rasidagic, F., Krivokapic, D., Corluka, M., \& Bjelica, D. (2017). Stature and Its Estimation Utilizing Arm Span Measurements in Male Adolescents from Federation of Bosnia and Herzegovina Entity in Bosnia and Herzegovina. Montenegrin Journal of Sports Science and Medicine, 6(1), 37-44.

Golshan, M., Amra, B., \& Hoghogi, M.A. (2003). Is arm span an accurate measure of height to predict pulmonary function parameters? Monaldi Archives for Chest Disease, 59(3), 189-192.

Golshan, M., Crapo, R.O., Amra, B., Jensen, R.I., \& Golshan, R. (2007). Arm span as an independent predictor of pulmonary function parameters: validation and reference values. Respirology, 12(3), 361-366.

Grasgruber, P., Popovic, S., Bokuvka, D., Davidovic, I., Hřebíckova, S., Ingrova, P., Potpara, P., Prce, S., \& Stracarova, N. (2017). The mountains of giants: an anthropometric survey of male youths in Bosnia and Herzegovina. Royal Society Open Science, 4, 161054.

Hickson, M., \& Frost, G.A (2003). Comparison of three methods for estimating height in the acutely ill elderly population. Journal of Human Nutrition and Dietitian, 16(1), 1320.

Jalzem, P.F., \& Gledhill, R.B. (1993). Predicting height from arm span measurements. Journal of Pediatric Orthopedics, 13(6), 761-765. 
Kanchan, T., Menezes, R.G., Moudgil, R., Kaur, R., Kotian, M.S. \& Garg, R.K. (2008). Standing height estimation from foot dimensions. Forensic Science International, 179(2/3), 241e1-245e1.

Komunat e Kosovës (2013). Pristina: Gjiganti. Retrieved on March 25, 2017, from http://www.gjiganti.com/kosova/ komunat/.

Marfell-Jones, M., Olds, T., Stew, A.D. \& Carter, J.E.L. (2006). International standards for anthropometric assessment. Potchesfstroom: International Society for the Advancement of Kinanthropometry.

Milasinovic, R., Popovic, S., Matic, R., Gardasevic, J. \& Bjelica, D. (2016a). Body Height and its Estimation Utilizing Arm Span Measurements in Male Adolescents from Southern Region in Montenegro. Sport Mont, 14(2), 21-23.

Milasinovic, R., Popovic, S., Jaksic, D., Vasilejvic, I. \& Bjelica, D. (2016b). Stature and its Estimation Utilizing Arm Span Measurements in Feale Adolescents from Southern Region in Montenegro. Sport Mont, 14(3), 15-18.

Mohanty, S.P., Babu, S.S., \& Nair, N.S. (2001). The use of arm span as a predictor of height. A study of South Indian women. Journal of Orthopedics Surgery, 9(1), 19-23.

Popovic, S. (2016). Body Height and its Estimation Utilizing Arm Span Measurements in Montenegrin Adults: National Survey. In Book of Summaries of 11th FIEP European Congress "Anthropological Aspects of Sport, Physical Education and Recreation" (5-6), Banjaluka: University of Banjaluka, Faculty of Physical Education and Sport.

Popovic, S. (2017). Local Geographical Differences in Adult Body Height in Montenegro. Montenegrin Journal of Sports Science and Medicine, 6(1), 81-87.

Popovic, S., Arifi, F., \& Bjelica, D. (2017). Standing Height and its Estimation Utilizing Foot Length Measurements in Kosovan Adults: National Survey. International Journal of Applied Exercise Physiology, 6(2), 1-7.

Popovic, S., \& Bjelica, D. (2016). Body Height and its Estimation Utilizing Arm Span Measurements in Kosovan Adolescence: National Survey. In Abstract Book of International Eurasian Conference on Sport, Education, and Society (9), Antalya: International Science Culture and Sport Association.

Popovic, S., \& Bjelica, D. (2017). Body Height and its Estimation Utilizing Foot Length Measurements in Kosovan Adults: National Survey. In Abstract Book of the Sport Science Conference AESA 2017 (2), Amol: Faculty of Sport
Sciences, Shomal University; Asian Exercise and Sport Science Association.

Popovic, S., Bjelica, D., Georgiev, G., Krivokapic, D., \& Milasinovic, R. (2016). Body Height and its Estimation Utilizing Arm Span Measurements in Macedonian Adults. Anthropologist, 24(3), 737-745.

Popovic, S., Bjelica, D., Molnar, S., Jaksic, D., \& Akpinar, S. (2013). Body Height and Its Estimation Utilizing Arm Span Measurements in Serbian Adults. International Journal of Morphology, 31(1), 271-279.

Popovic, S., Bjelica, D., Tanase, G.D. \& Milasinovic, R. (2015). Body Height and Its Estimation Utilizing Arm Span Measurements in Bosnian and Herzegovinian Adolescents. Montenegrin Journal of Sports Science and Medicine, 4(1), 29-36.

Quanjer, P.H., Capderou, A., Mazocioglu, M.M., Aggarwal, A., Popovic, S., Datta Banik, S., Tayie, F.A.K., Golshan, M., Ip, M.S.M., \& Zelter, M. (2014). All-age relationship between arm span and height in different ethnic groups. European Respiratory Journal, 44(4), 905-912.

Reeves, S.L., Varakamin, C. \& Henry, C.J. (1996). The relationship between arm-span measurements and height with special reference to gender and ethnicity. European Journal of Clinical Nutrition, 50(6), 398-400.

Singh, A., Kumar, A., Chavali, K.H., \& Harish, D. (2012). Use of arm-span and foot length for estimation of height of the person. Journal of Punjab academy of forensic medicine and toxicology, 12(2), 87-91.

Szollosi, E. (1998). Secular trend in Debrecen university students (in Hungerian). Anthropologiai Kozlemények, 39, 4351.

Steele, M.F., \& Chenier, T.C. (1990). Arm-span, height and age in black and white women. Annals of Human Biology, 17(6), 533-541.

Uhrova, P., Benus, R., Masnicova, S., Obertova, Z., Kramarova, D., Kyselicova, K., Dornhoferova, M., Bodorikova, S., \& Nescakova, E. (2015). Estimation of standing height using hand and foot dimensions in Slovak adults. Legal medicine, 17(2), 92-97.

Ter Goon, D., Toriola, A.T., Musa, D.I., \& Akusu, S. (2011). The relationship between arm span and stature in Nigerian adults. Kinesiology, 43(1), 38-43.

Wronka, I., \& Pawlinska-Chmara, R. (2009). Childhood environment and adult height among Polish university students. Collegium Antropologicum, 33(4), 1039-1045.

\section{S. Popovic}

University of Montenegro, Faculty for Sport and Physical Education, Narodne omladine bb, Niksic, Montenegro e-mail:stevop@ac.me 
